\title{
DRUMMOND E A POESIA SOCIAL
}

\section{DRUMMOND AND THE SOCIAL POETRY}

\author{
Marcelo Bortoloti \\ Museu de Arte Contemporânea da Universidade de São Paulo, São Paulo, São Paulo, Brasil \\ marcelobortoloti@gmail.com
}

Resumo: Na primeira metade dos anos 1940, o poeta Carlos Drummond de Andrade assumiu um engajamento político raro em sua trajetória, alinhado a ideias de esquerda e ao comunismo internacional. Esta postura refletiu-se tanto em sua conduta profissional, como funcionário no Ministério da Educação e Saúde, quanto em suas referências poéticas. Neste artigo são apresentados alguns aspectos de sua atuação política, e analisado o conceito de "poesia social", conforme entendimento do próprio Drummond, a partir de textos que ele publicou na imprensa da época. Este gênero de poesia, do qual passou a ser um grande entusiasta e defensor, iria influir diretamente na fatura de seu livro mais engajado, A rosa do povo, publicado em 1945.

Palavras-chave: Carlos Drummond de Andrade; Poesia Social; Segunda Guerra Mundial; Partido Comunista; Modernismo

Abstract: In the first half of the 1940s, the poet Carlos Drummond de Andrade assumed a rare political engagement in his trajectory, aligned with leftist ideals and international communism. This attitude was reflected both in his professional conduct, as an employee at the Ministry of Education and Health, and in his poetic references. In this article some aspects of his political performance are presented, and the concept of "social poetry" is analyzed, as understood by Drummond himself, based on texts that he published in the press of the time. This genre of poetry, of which he became a great enthusiast and defender, would directly influence the invoice of his most engaged book, A rosa do povo, published in 1945.

Keywords: Carlos Drummond de Andrade; Social Poetry; Second World War; Communist Party; Modernism 
Em 1942, mesmo ano em que Carlos Drummond de Andrade lançava o livro José, coletânea de poemas marcados pela melancolia e falta de esperança no futuro, iniciava a escrita dos versos que comporiam sua obra mais engajada, A rosa do povo. O primeiro poema que aparece nos jornais, em outubro daquele ano, é "Passagem da noite", que não deixa dúvidas sobre uma mudança em seu estado de espírito: "Tudo que à noite perdemos / se nos confia outra vez. / Obrigado, coisas fiéis!" (ANDRADE, 1942a, p. 1). O otimismo e a belicosidade que já vinham presentes em sua obra desde 1940, quando lançou Sentimento do mundo - atravessando um hiato pessimista em José - retornam de maneira muito mais expansiva neste momento, onde as posições políticas e ideológicas do autor ganham um inédito relevo.

O que parece ter feito o poeta a deixar para trás a melancolia de José para assumir a postura confiante de A rosa do povo foi uma mudança na marcha da Segunda Guerra Mundial. Em outubro de 1942, o Brasil ainda não tinha entrado no conflito, embora submarinos alemães houvessem afundado navios civis na costa brasileira. Mas já se podia sentir aqui os reflexos da Batalha de Stalingrado, que começou em julho. Esta batalha representou uma virada na guerra contra a Alemanha e uma reafirmação do poderio militar de Moscou. A União Soviética se levantava novamente como a grande inimiga do nazismo, e com ela todos os valores revolucionários que representava. A passagem da noite que Drummond enxerga ali é o início da derrota fascista pelo braço dos comunistas, e o retorno dos ideais socializantes de um mundo mais justo. A Segunda Guerra Mundial adquire neste momento o seu aspecto mais ideológico.

Para John Gledson, a autoconfiança do poeta surpreende neste momento tanto mais que não são rejeitados o ceticismo e a ironia congênitos de sua obra. Esses traços são aceitos e transcendidos dentro da própria confiança: "Drummond está consciente da importância e do alcance da sua poesia, da sua capacidade de refletir o mundo contemporâneo, de exprimir os sentimentos não só dele mesmo como também dos seus semelhantes" (GLEDSON, 1981, p. 163). Existe ao longo do livro uma espécie de tensão dialética, que Iumna Maria Simon define como a tensão entre a viagem no mundo e a viagem no quarto. Ou seja, o embate entre o presente, a temática coletiva, a comunicação e a objetividade de um lado, e o passado individual, a contemplação e a subjetividade do outro, que formam o núcleo gerador da expressão poética do livro (SIMON, 1978, p. 136).

Esta tensão não ofusca a adesão ideológica que surge em primeiro plano no livro $A$ rosa do povo, sobrepondo-se inclusive ao retrato do conflito bélico do qual o Brasil tomou parte. É um livro que expressa ideias socializantes e marxistas, absorvendo a influência de autores como o russo Vladmir Maiakovisky, o chileno Pablo Neruda, os poetas comunistas que lutaram na Guerra da Espanha e os escritores que continuavam produzindo peças de resistência na França ocupada. Como foi publicado depois da queda do Estado Novo, pôde explorar de maneira mais aberta a temática política, como no poema "Fim da Terceira Internacional", sobre o encerramento do Komintern, escrito em 1943, e que acabou saindo com o título "Mas viveremos". Diziam alguns desses versos que também foram modificados na versão final: "Mas um livro, por baixo do colchão, / era súbito um beijo, uma carícia, / uma paz sobre o corpo se alastrando, / e teu retrato, Lênin, consolava" (ANDRADE, 2012, p. 208). ${ }^{1}$

O escritor José Maria Cançado, autor da biografia Os sapatos de Orfeu, entrevistou um sobrinho do poeta, Heraldo Drummond de Andrade, que morou com ele no Rio de Janeiro

\footnotetext{
${ }^{1} \mathrm{O}$ sentimento ideológico já movia o poeta enquanto ele continuava trabalhando sob a ditadura do Estado Novo, embora não pudesse extravasá-lo claramente. Em 1943, Drummond enviou uma cópia datiloscrita de "O fim da Terceira Internacinal" ao amigo Abgar Renaut, que vinha acompanhada do seguinte bilhete: "Leia e.... rasgue". (ANDRADE, 2012, p. 208).
} 
em 1942. O sobrinho descreveu desta forma sua posição política na época: "Ele [Drummond] via os russos e o regime soviético como um caminho necessário, incontornável, que tinha que ser tomado mesmo, e que estava se tornando comunista porque não havia outro caminho a seguir". Ainda segundo Heraldo Drummond, o poeta via na "ditadura do proletariado" a melhor solução para se chegar a um estágio mais alto da sociedade (apud CANÇADO, 1993, p. 178).

Tal postura ideológica, como se verá adiante, interferiu tanto em sua conduta profissional como na maneira e encarar a poesia. Dentro do governo, começava-se a operar uma discreta mudança na postura anticomunista, declarada desde 1935 quando Luís Carlos Prestes liderou a frustrada tentativa de golpe. No momento em que o Brasil declarou guerra à Alemanha e à Itália, naquele mesmo ano de 1942, a Rússia passou a ser vista como uma aliada militar. O país símbolo do comunismo era o responsável pelos principais avanços no combate ao fascismo internacional. E o governo teve de conviver com este parceiro - e consequentemente com todos os valores ideológicos que carregava. Neste momento, o discurso do Estado Novo e o do Partido Comunista passaram a ter muitos pontos de convergência.

Drummond valeu-se desta confluência como funcionário público que era, ocupando a chefia de gabinete no Ministério da Educação e Saúde. Na época, além de poesia bélica engajada que produziu, fez discursos no rádio e em cerimônias públicas, num aguerrido antifascismo que convinha à sua visão simpática a Moscou. Em janeiro de 1942, foi convidado a ser paraninfo dos formandos da Escola Nacional de Música, no Rio de Janeiro. No discurso de saudação aos recém-graduados, publicado na revista Continental com o título "A função da música em tempo de luta", Drummond dizia aos alunos que iniciavam a carreira na área da música que nenhum intelectual poderia ficar indiferente à guerra, pois este conflito ameaçava a própria criação artística:

Desejo aludir antes às transformações de substância e de essência que uma conflagração de caráter tão nitidamente revolucionário como é a atual poderia trazer à música ou a qualquer das outras artes. Imaginemos por instantes a vitória das forças conduzidas pelo mito da superioridade de raça e pela negação da personalidade livre. Que espécie de música poderia existir no mundo subsequente? A dos tanques e bombardeiros uivantes? A música de propaganda ou a de anestesia? (ANDRADE, 1942b, p. 29).

Em dezembro daquele ano, o poeta representou o ministro Gustavo Capanema na formatura dos secundaristas do Ginásio São Miguel, na cidade de Passa Quatro, interior de Minas. Seu discurso, mais uma vez inflamado, certamente impactou os desavisados estudantes: "O que acontece nas ilhas Salomão repercute em vosso aparentemente tranquilo Passa Quatro" (ANDRADE, 1942c, p. 1). Segundo Drummond, os jovens alunos poderiam participar de maneira efetiva na campanha nacional:

Pelo Brasil a fora, meninos e rapazes estão dando espontaneamente metais à nossa indústria bélica, aviões à nossa força aérea, elementos auxiliares à nossa defesa passiva. Não posso esquecer-me daquele menino anônimo que, nas ruas do Rio, há dois ou três meses atrás, montava guarda, vigilante, a uma pirâmide de objetos metálicos. Esse menino estava um pouco por toda a parte, nas grandes e nas humildes cidades do Brasil, pequenino soldado de uma grande causa, companheiro despretensioso de outros soldados, disposto a servir, a ajudar, a fazer força pela nossa vitória. (ANDRADE, 1942c, p. 1).

Este tipo de fala casava-se tanto com a postura do governo quanto com a posição ideológica do poeta. $\mathrm{O}$ esforço de guerra era uma luta nacional que coincidia com aspirações 
políticas muito concretas da esquerda. Quando o país enviou os soldados da Força Expedicionária Brasileira para lutar na Itália ao lado dos Aliados, Drummond esteve no centro do Rio para participar do desfile de despedida destes militares. Em seguida escreveu um artigo na Folha Carioca, com teor altamente patriótico, que em alguns trechos chega a aproximar a ideia da guerra com a da revolução: "Nunca soldados foram tão amados, nunca o povo esteve tão perto deles, nunca se compreenderam tanto" (ANDRADE, 1944a, p. 1).

$\mathrm{O}$ artigo lhe valeu um telegrama de cumprimento por parte de um grupo de comunistas liderado por Aydano do Couto Ferraz, que integrava a Liga de Defesa Nacional. ${ }^{2}$ Dizia a mensagem que sua crônica no jornal "esposou pontos de vista [que] constituem a base [da] nossa pregação patriótica" (FERRAZ, 1944). Na crônica, Drummond estava bastante afinado com os propósitos da liga, que naquele momento fazia uma cruzada contra o nazismo. Dizia o artigo:

(...) E nós, que ficávamos nessa retaguarda mansa da Avenida, começávamos a descobrir confusamente que também podíamos fazer alguma coisa, menos é certo que aqueles soldados, mas completando e garantindo a ação deles, nas tarefas que nos compete e nas outras que podemos acrescentar-lhe. O sentido geral e complexo da guerra, suas infinitas ramificações e aspectos, sua característica de ser ao mesmo tempo militar, econômica, política, social, sua faminta exigência de trabalho e dedicação sob todas as formas, nos apareciam com essa realidade explosiva e convincente que só a emoção pode suscitar, diante dos expedicionários marchando. (ANDRADE, 1944a, p. 1).

Esta confluência de interesses foi útil à postura de Drummond também nos bastidores do governo. Em 1942, após declarar guerra ao Eixo, Getúlio Vargas determinou que fosse criada no interior de cada ministério uma comissão para avaliar a existência de espiões - os chamados "quintas-colunas" - atuando no serviço público. O poeta foi presidente da Sessão de Segurança Nacional do Ministério da Educação e Saúde. Um relatório de agosto de 1942, assinado por ele e outros três membros, é bastante contundente quanto ao uso político deste tipo de comissão. O documento procurava atingir os integralistas liderados por Plínio Salgado, inimigos históricos do Partido Comunista.

Naquela altura, a Ação Integralista Brasileira já havia sido posta na ilegalidade e seus dirigentes estavam presos. Se em 1937 os integralistas ajudaram Vargas no combate ao perigo comunista, no ano seguinte, quando esperavam uma posição mais relevante dentro do governo, foram postos de lado. Com isto, o grupo articulou um golpe de estado que chegou a invadir a residência presidencial, mas a intentona foi rapidamente sufocada. A partir daí, a Ação Integralista passou a ser tão perseguida quanto o Partido Comunista. Quando o Brasil entrou na guerra contra Alemanha e Itália, lutando ao lado da União Soviética, os integralistas sofreram novo revés, já que eram tradicionais apoiadores dos regimes fascistas. A comoção provocada pelo afundamento dos navios brasileiros, que teve ajuda de espiões alemães em território nacional, intensificou o sentimento de repúdio aos integralistas. E o Partido Comunista viu neste momento uma oportunidade de intensificar a campanha contra os antigos adversários.

Ligados ao Ministério da Educação, trabalhavam integralistas como Thiers Martins Moreira, que era secretário no Departamento Nacional de Educação, e Othon Henri Leonardos,

\footnotetext{
${ }^{2}$ Esta organização, criada por Olavo Bilac em 1916, estava àquela altura tomada pelos esquerdistas perseguidos pelo Estado Novo, mas que então ajudavam as campanhas do governo, como a do envio da FEB para a Itália ou das doações de metais por parte da população civil. Campanhas que encontraram no poeta um verdadeiro portavoz.
} 
professor da Universidade do Brasil. O relatório reservado que Drummond assinou indicava a necessidade de se tomar uma providência em relação a eles: a exclusão do quadro de funcionários. A comissão, cujo objetivo era verificar a existência de espiões no âmbito do ministério, além de sugerir o expurgo dos integralistas, indicava o mesmo quanto aos estrangeiros que trabalhavam na repartição. Dizia o relatório:

No tocante aos estrangeiros, não hesita a Comissão em considerar nocivos todos os naturais dos países chamados do Eixo, não apenas da Alemanha e Itália, com os quais estamos em guerra, mas também os países que, nesta guerra mundial, combatem ao lado dessas nações (ANDRADE et al, 1941).

Também em relação aos naturalizados brasileiros, a Comissão sugeria medidas severas:

Quanto aos naturalizados brasileiros, naturais dos países do Eixo, entende a Comissão que devam ser incluídos na categoria dos suspeitos, pois é sabido que as suas naturalizações raramente ou quase nunca obedecem a um sentimento de completa identificação com a pátria adotiva, mas ao contrário, na sua grande maioria, são inspiradas por motivos de natureza egoística, sendo mesmo em alguns casos, mais raros, obtidas com intuitos traiçoeiros. (ANDRADE et al, 1941).

O relatório avaliava que o governo deveria tomar medidas não apenas em relação aos elementos "nocivos", mas também àqueles que poderiam ser considerados "suspeitos", que "por seus antecedentes" poderiam causar algum prejuízo à causa brasileira. E observava que, a serviço do ministério, atuavam alguns funcionários que "tiveram papel destacado na Ação Integralista Brasileira, uns como doutrinadores e propagandistas, outros em funções de natureza deliberativa ou executiva". Diante disto, sugeria a adoção de algum tipo de providência:

(...) é evidente que a circunstância de não se tomar qualquer providência a seu respeito não concorre para elevar o prestígio do Ministério na opinião pública, mas ao contrário desperta contra o governo a suspeita de que não seja sincero no seu propósito de combater a "quinta-coluna". (ANDRADE et al, 1941).

O Programa de Ação do ministério para a guerra, aprovado em reunião de 10 de setembro de 1942, indicava medidas como a realização de um censo dos funcionários e alunos da rede de ensino para eventual convocação, utilização da estrutura das escolas técnicas para fabricar material bélico e medidas de profilaxia da peste e da malária em áreas de interesse militar.

Além disso, falava da necessidade de propaganda cívica nas escolas, rádios e jornais com objetivo de "esclarecer, orientar e entusiasmar os estudantes e, através deles, a massa popular" acerca da campanha de guerra (PROGRAMA DE AÇÃO..., 1942). Não tinham outro objetivo os discursos de Drummond no rádio e nas escolas, como paraninfo ou representando Capanema.

\section{O poeta social}

Confluindo com esta postura no ministério, a nova orientação que Drummond deu à sua poesia a partir de 1942, tinha também em sua base um elemento ideológico. A preocupação com o coletivo, ausente de suas primeiras experiências literárias até 1934, passava a ser uma referência, ou, mais do que isso, um propósito da sua escrita, pelo menos naquele momento. Diante do conflito bélico e político que se travava sobretudo na Europa, mas no qual o Brasil 
estava intimamente envolvido, os escritores deveriam assumir um papel ativo, segundo seu entendimento, orientado a poesia para causas mais amplas que suas angústias pessoais. Neste contexto, ganhava relevância o gênero que Drummond definia como "poesia social", do qual o poeta se tornou um grande entusiasta e defensor, e cujos reflexos iriam aparecer claramente em A rosa do povo.

Em 1944, sua fama como poeta social já era corrente. Drummond dava palestras e escrevia artigos sobre o tema, intimamente ligado à produção literária comunista. A atividade não era vista como subversiva dentro de um governo que agora lutava ao lado da Rússia. Em fevereiro daquele ano, o poeta proferiu conferência sobre "O sentido social da poesia", no Centro Israelita de Niterói. Em crônica que escreveu a respeito do assunto no jornal Folha Carioca, o poeta dizia que, ao final da palestra, foi cercado por moças e rapazes na faixa dos 18 anos, ávidos por saber um pouco mais sobre a participação social que se impunha ao artista naquele momento. Um deles perguntou se, como tema para uma obra de arte, valiam a mesma coisa uma paisagem ou um imigrante. O jovem ouviu de Drummond a seguinte resposta: "A paisagem e o imigrante são igualmente assuntos, mas o imigrante ganha da paisagem por ser também um sujeito igual a nós, um companheiro, que pode não se deixar pintar ou maltratar com a mesma docilidade..." (ANDRADE, 1944b, p.1).

Três meses depois, jornais do Rio de Janeiro como o Correio da Manhã e a Folha Carioca noticiaram que Drummond estava realizando uma pesquisa de fôlego com grande interesse para a literatura e a política: preparava uma antologia da poesia social brasileira. Segundo informação do Correio da Manhã, o objetivo do organizador era mostrar a constância do gênero na literatura brasileira, em diversas épocas, escolas e tendências. "E a sua antologia não incluirá só a literatura erudita, mas também a popular, os versos do folclore. A divisão não será cronológica, mas por assuntos: os políticos, os sociais, os científicos" (ANTOLOGIA BRASILEIRA....1944). De acordo com o texto, Drummond escreveria uma introdução, na qual iria explicar seus estudos e pesquisas sobre o tema. O projeto, no entanto, nunca foi concluído. 3

O pensamento de Drummond sobre poesia social ficou muito bem documentado numa série de artigos que escreveu para a Folha Carioca, publicados durante três finais de semana no mês de abril de 1944. Os textos foram sistematizados como uma espécie de introdução ao tema. No primeiro, com o título "Poesia Social I - Definição", ele fazia uma apresentação do seu conceito deste tipo de literatura; no segundo, "Poesia Social II - Evolução", explicava o desenvolvimento desta poesia no Brasil; no terceiro, "Poesia Social III - Conclusão", enumerava nove pontos que considerava centrais para a compreensão do gênero e sua evolução futura. No artigo em que define o objeto, Drummond observava que poesia social é aquela que se dirige preferencialmente a uma classe social, ou que dela tira seus elementos de criação. Em

\footnotetext{
${ }^{3}$ Este interesse refletia no seu gosto literário de então. Em carta de 1943 a Fernando Sabino, Drummond se mostra bastante empolgado com Vladimir Maiakovski, o "poeta da Revolução" que participou ativamente da política russa no princípio do século XX. Diz um trecho: "Quanto ao Maiakovski, concordo com você: ele é o tal. Quando a gente lê um sujeito desses fica-se perguntando onde estão os poetas do Brasil! Parece que não estão em parte alguma. Tive a mesma sensação lendo uma antologia de poetas latino-americanos" (ANDRADE, 1943a). Dois meses antes desta carta, escreveu um artigo para a revista "Leitura", condenando o livro A Montanha Mágica, de Thomas Mann, pelo ambiente doentio e de opressão a que ele nos confina. Diz o texto: "Decerto não pedimos ao autor que pense por nós, que resolva nossos problemas. Mas temos o direito de pedir-lhe que nos esclareça um pouco, e nos ajude a resolvê-los, ou pelo menos não nos estorve na solução. (...) A leitura é uma experiência crítica e uma experiência humana. É também um dado de confiança, um abandono. Podemos abandonar-nos a esse ambiente de febre sem esperança e de análise sem resultado?” (ANDRADE, 1943b, p. 1).
} 
outras palavras, uma poesia não dirigida ao indivíduo, mas ao grupo do qual ele participa, e inspirada na existência coletiva, e não na individual.

Segundo Drummond, tal poesia existia em países tão ideologicamente díspares como a União Soviética, a Inglaterra e o Chile. E seus poemas eram muitas vezes mal lidos e mal compreendidos. Ele prosseguia: "Cada leitor que os descobre e que abre mão de preconceitos é como se recebesse no rosto o sopro de um vento do mar, cheio de sal e iodo, e o apelo de portos longínquos". Drummond afirmava que o propósito do gênero era "melhorar as condições sociais". Para isto, ele deveria apresentar-se como uma poesia "boa em si", interessada pelos elementos formais que estão "na base de qualquer construção poética" (ANDRADE, 1944c, p. 1). Em paralelo a esta preocupação estética, o escritor deveria estar atento à renovação do mundo e a seu interesse particular pelos outros:

E aqui está um duplo e sedutor trabalho para o poeta: trabalhar para que o mundo se renove, mas renovar-se ele mesmo, e dar com isto o exemplo da renovação. Fazer pouco caso de si mesmo, e muito caso dos outros. Debruçar-se o mais possível sobre os semelhantes, e fazê-lo como fazem os romancistas, os contistas, os repórteres, todos aqueles que preocupam em colher e exprimir sentimentos e aspirações alheias. (ANDRADE, 1944c, p. 1).

No segundo artigo, em que tratava da evolução da poesia social no Brasil, Drummond observou que o poeta que se dedicava ao gênero naquele momento praticamente não tinha antepassados no país. Exceção única feita a Castro Alves que, apesar do "frequente mau gosto de suas imagens" e da "facilidade meio ingênua de seus arroubos", conseguiu, em alguns de seus poemas, exprimir muito precisamente o caráter social da poesia e a missão do escritor na sociedade, "sem traição à sua condição de poeta e de artista". (ANDRADE, 1944d, p. 1).

Depois de Castro Alves, ele salientava que o grande avanço para os poetas de interesse social foi o advento do modernismo. Ao romper com a tradição clássica, abolindo as formas arcaicas de construção poética, o movimento abriu caminho para conquistar a "forma revolucionária" da escrita. Segundo Drummond, esta forma livre facultou aos poetas o registro de sentimentos e impressões mais complexas, sem recorrer a truques e automatismos:

A conquista dessa forma, eu a considero fundamental para o trabalho do nosso poeta
de caráter social. Se é possível fazer um soneto revolucionário, é muito mais possível
não fazê-lo. A disciplina formal rígida que o sonetista se impõe como que o induz a
não abordar o tema rebelde e demasiado plástico que mal se encaixaria na forma de
cimento ou mármore daquela composição. (ANDRADE, 1944d, p. 1).

Este otimismo em relação ao modernismo não era compartilhado por muitos escritores que participaram do movimento. O próprio Mário de Andrade, no balanço que fez em 1942, reconheceu sua utilidade na conquista do "direito permanente à pesquisa estética", mas nem tanto em relação à "atualização da inteligência artística" no país. (ANDRADE, M., 1942). Segundo João Luiz Tafetá, não houve no movimento de 1922 uma aspiração que transbordasse os quadros da burguesia. A ideologia de esquerda não encontrou eco nas obras da chamada "fase heroica" do modernismo, e somente no decênio de 1930, com o recrudescimento da luta ideológica no mundo, houve alguma modificação do seu projeto inicial.

De acordo com o crítico, enquanto neste momento "heroico" a ênfase das discussões recaía predominantemente sobre o projeto estético, numa segunda fase, a partir de 1930, a ênfase foi o projeto ideológico, com discussões sobre o papel do escritor e da função da literatura. "Uma das justificativas apresentadas para explicar tal mudança de enfoque diz que o 
modernismo, por volta de 1930, já teria obtido ampla vitória do seu programa estético e se encontrava, portanto, no instante de se voltar para outro tipo de preocupação". (LAFETÁ, 2004, p. 63).

Voltando aos textos de Drummond, no terceiro artigo ele tocava no principal ponto de cisão entre suas ideias e a dos comunistas ortodoxos, que era no fundo o tema central de embate entre este grupo e os primeiros modernistas. Se para o poeta foi o modernismo que abriu espaço para a emancipação da poesia de caráter social, os adeptos do movimento eram vistos pelo Partido Comunista, pelo contrário, como autores que não dialogavam com o povo em razão do seu hermetismo. Diz o artigo:

Cada poeta precisa fabricar seus moldes peculiares de expressão, e não adotar aqueles que mais facilmente o conduzam ao público. Cabe a este apanhar o que há de específico no poeta, e amá-lo e compreendê-lo por isto. Não há poetas obscuros: há maus poetas, que se exprimem mal. O que haja de velado, de misterioso, de requintado, de alarmante, de sutil em uma poesia não constitui embaraço intransponível para sua comunicação com o público. Se o público é ignorante, instruamos o público; se tem o gosto pervertido, restauremos-lhe o gosto. Mas quando se dá ao público o pior de cada arte, seria injusto culpá-lo de não aceitar o melhor. (ANDRADE, 1944e, p. 1).

Ao final deste artigo, Drummond enumerou nove pontos sobre poesia de caráter social, no melhor espírito revolucionário. Nos quatro primeiros ele sintetizava o que disse em artigos anteriores, salientando que o gênero tende a conciliar indivíduo e massa, representando artisticamente os movimentos coletivos de inquietação e reivindicação, sem estar subordinado a interesses políticos, mas em harmonia com os princípios de justiça, solidariedade e correta divisão dos bens - princípios estes eminentemente comunistas. Voltava a falar da importância do modernismo para este tipo de expressão artística, mas lamentava que a maior parte dos poetas modernos fosse indiferente às aspirações desta poesia. A partir do quinto ponto, ele lançava as bases para o desenvolvimento da poesia social no Brasil:

$\left.1^{\circ}\right)$ A poesia moderna de caráter social tende a conciliar indivíduo e massa, exprimindo aquele através desta, e representando artisticamente os movimentos coletivos de inquietação e reivindicação, refletindo-os, animando-os ou orientando-os sem subordinação a interesses políticos mas em harmonia com os princípios sociais de justiça, solidariedade e boa distribuição dos bens necessários à vida e à dignidade do homem.

$\left.2^{\circ}\right)$ No Brasil, reconhecida a ascendência histórica e a supremacia de Castro Alves, essa poesia, com tendência a incorporar temas, processos e objetivos específicos, resulta diretamente do movimento literário modernista, embora o tenha ultrapassado, e é feita por intelectuais da chamada classe média.

$3^{\circ}$ ) A falta, entre nós, de uma poesia de caráter social realizada diretamente por representantes das classes trabalhadoras explica a debilidade dos ensaios feitos por elementos de outra camada, desejosos de exprimir liricamente os ensaios coletivos, mas que obviamente não são os mais preparados ou qualificados para fazê-lo.

$4^{\circ}$ ) A maioria dos poetas do modernismo brasileiro, movimento de que originou a poesia de sentido social, é, por uma contradição explicável, indiferente, deliberada ou inconscientemente, às aspirações desta poesia. 
$5^{\circ}$ ) É preciso portanto tirar do povo, nas suas camadas mais autênticas, ainda em preparação nas escolas, e nos quadros da vida do trabalho, as vozes que darão a essa espécie de poesia todo o vigor, volume e repercussão que ela deve ter, como elemento de beleza e de libertação intelectual.

$\left.6^{\circ}\right)$ Nossa poesia do futuro, poderosa, dramática e rica de virtualidades afetivas, matiz nacional de extraordinário interesse será o constituído pela poesia negra, feita pelos trabalhadores negros brasileiros e recolhendo todo o passado de lutas e riqueza amorosa de sua raça.

$\left.7^{\circ}\right)$ O processo de formação dos núcleos de povoação através da cata dos minerais preciosos, a criação de zonas distintas de civilização agrária, pastoril e urbana, a história das lutas libertárias no Brasil são grandes temas poéticos quase totalmente inexplorados e que estão pedindo urgentemente a atenção dos poetas brasileiros. A própria atualidade nos fornece um tema riquíssimo e por si só capaz de reconciliar o poeta com os homens de seu tempo; a canção do expedicionário.

$8^{\circ}$ ) Nossa verdadeira poesia de caráter social será profundamente brasileira mas universalista, e contribuirá para a integração do Brasil no conjunto de nações organizadas e orientadas no sentido de fraternidade e justiça, que se procura estabelecer através da presente guerra mundial.

$9^{\circ}$ ) A grande forma poética de todos os tempos é a epopeia, e deve ser este o poema cuja concepção tente o poeta brasileiro do futuro, que conseguirá levar a poesia do Brasil ao conhecimento do mundo. (ANDRADE, 1944e, p. 1).

Drummond acreditava numa poesia de caráter universal, que pudesse unir os trabalhadores do mundo todo, tal qual os propósitos da Terceira Internacional. Mas tinha em mente que esta poesia deveria surgir do povo, fruto da própria emancipação das massas, e não através de uma interpretação de intelectuais da elite sobre os anseios da classe trabalhadora. No Brasil, ele via na figura do negro liberto da opressão escravocrata, na história da colonização mineira que se baseou também na escravidão como sustentação econômica, ou na participação dos soldados brasileiros na Segunda Guerra Mundial, temas a se explorar para a produção desta poesia universalista. Ela deveria ter a forma épica, gênero supostamente de maior alcance popular. Este conjunto de ideias estava na base e iria permear a fatura do seu livro mais político, A rosa do povo, publicado no ano seguinte.

\section{Referências}

ANDRADE, C. D. Passagem da Noite. A manhã, Rio de Janeiro, 18 de outubro de 1942a.

ANDRADE, C. D. Poesia 1930-62. Edição crítica de Júlio Castañon Guimarães. São Paulo: Cosac Naify, 2012

ANDRADE, C. D. A função da música em tempo de luta. Continental, Rio de Janeiro, maio de $1942 b$.

ANDRADE, C. D. A saudação do senhor Carlos Drummond de Andrade. Cruzeiro do Sul, Passa Quatro, 27de dezembro de 1942c. 
ANDRADE, C. D. Soldado que vai para a Guerra. Folha Carioca, Rio de Janeiro, 3 de abril de 1944a.

ANDRADE, C. D. Noite em Niterói. Folha Carioca, Rio de Janeiro, 7 de fevereiro de 1944b.

ANDRADE, C. D. Poesia Social I - Definição. Folha Carioca, Rio de Janeiro, 10 de abril de 1944c.

ANDRADE, C. D. Poesia Social II - Evolução. Folha Carioca, Rio de Janeiro, 17 de abril de 1944d.

ANDRADE, C. D. Poesia Social III - Conclusão. Folha Carioca, Rio de Janeiro, 24 de abril de 1944 e.

ANDRADE, C. D. [Correspondência]. Destinatário: Fernando Sabino. Rio de Janeiro, 18 de junho de 1943a. Acervo Fernando Sabino. Fundação Casa de Rui Barbosa.

ANDRADE, C. D. Febre, tosse e Thomas Mann. Leitura, Rio de Janeiro, abril de 1943b.

ANDRADE, C. D., et al. Relatório Reservado de 31 de agosto de 1941. Pasta Assuntos relativos à Guerra. Arquivo Gustavo Capanema. Fundação Getúlio Vargas, Rio de Janeiro.

ANDRADE, M. "O Movimento Modernista", 1942. Consultado em http://www.vermelho. org.br/noticia/175420-11.

ANTOLOGIA BRASILEIRA DA POESIA SOCIAL, autor desconhecido. Correio da Manhã , Rio de Janeiro, 14 de maio de 1944.

FERRAZ, A. C. [Correspondência]. Destinatário: Carlos Drummond de Andrade. Telegrama. Rio de Janeiro, 3 de abril de 1944. Acervo Carlos Drummond de Andrade, Fundação Casa de Rui Barbosa.

GLEDSON, J. Poesia e poética de Carlos Drummond de Andrade. São Paulo: Duas Cidades. 1981.

LAFETÁ, J. L. A dimensão da noite. São Paulo: Duas cidades; Editora 34, 2004.

PROGRAMA DE AÇÃO DO MINISTÉRIO DA EDUCAÇÃO PARA A GUERRA, autor desconhecido. Rio de Janeiro, 10 de setembro de 1942. Pasta Assuntos relativos à Guerra. Arquivo Gustavo Capanema. Fundação Getúlio Vargas, Rio de Janeiro.

SIMON, I. M. Drummond, uma poética do risco. São Paulo: Ática, 1978.

Recebido em: 31 de julho de 2020 Aceito em: 01 de dezembro de 2020

Publicado em dezembro de 2020 